\title{
A THEORETICAL STUDY ON THE MECHANISM OF THE ADDITION REACTION BETWEEN CYCLOPROPENYLIDENE AND ETHYLENE
}

\author{
XIAOJUN TAN ${ }^{*, a}$, ZHEN LI ${ }^{b}$, QIAO SUN ${ }^{b}$, PING LI ${ }^{*, c}$, WEIHUA WANG ${ }^{c}$, GUORONG WANG ${ }^{a}$ \\ $\left({ }^{a}\right.$ College of Medical and Life Science, University of Jinan, Jinan, Shandong, 250022, People's Republic of China) \\ ('Australian Institute for Bioengineering and Nanotechnology, The University of Queensland, QLD 4072, Australia) \\ (c School of Chemistry and Chemical Engineering, Qufu Normal University, Qufu, Shandong, 273165, People's Republic of China)
}

(Received: December 20, 2011 - Accepted: March 15, 2012)

\begin{abstract}
The reaction mechanism between cyclopropenylidene and ethylene has been systematically investigated employing the MP2/6-311+G* level of theory to better understand the cyclopropenylidene reactivity with unsaturated hydrocarbons. Geometry optimization, vibrational analysis, and energy property for the involved stationary points on the potential energy surface have been calculated. Energies of all the species are also further refined by the CCSD(T)/6-311+G* single-point calculations. Firstly, one important reaction intermediate (INTa) has been located via a transition state (TSa). After that, the common intermediate (INTb) for the two pathways (1) and (2) has been formed via TSb. At last, two different products possessing three- and four-membered ring characters have been obtained through two reaction pathways. In the reaction pathway (1), a three-membered ring alkyne compound has been obtained. As for the reaction pathway (2), a four-membered ring conjugated diene compound has been formed, which is the most favorable reaction to occur from the kinetic and thermodynamic viewpoints.
\end{abstract}

Keywords: Cyclopropenylidene, Ethylene, Addition reaction, Theoretical study.

\section{INTRODUCTION}

Carbene can be defined as a divalent carbon intermediate, where the carbene carbon is linked to two adjacent groups by covalent bonds and possesses two nonbonding electrons. It is well known that carbene plays an important role in organic chemistry, especially for the addition reaction with $\mathrm{C}=\mathrm{C}$ and $\mathrm{C}=\mathrm{O}$ double bond ${ }^{1-4}$. Therefore, the studies of carbene have attracted more attentions theoretically and experimentally. For example, carbene can be used to provide simple and direct synthesis for small-ring, highly strained compounds, as well as those that are hardly synthesized through conventional ways $s^{5}$. The reactions between carbene or substituted carbene and some small molecules have been studied theoretically by $\mathrm{Lu}$ et al. ${ }^{6-8}$. Apeloig et al. extensively studied the mechanisms and stereoselectivity of carbene addition to olefin experimentally and theoretically ${ }^{9-10}$. Recently, the reactions between carbene and small-ring strained molecules, such as epoxyethane and azacyclopropane, have been investigated theoretically $\mathrm{y}^{11-12}$.

As the simplest vinylidene carbenes, $\mathrm{C}_{3} \mathrm{H}_{2}$ is a class of highly unsaturated carbenes, which are of great interest for the chemistry of carbon-rich gasphase environments. As displayed in Scheme 1, three isomers have been located on its potential energy surface. Here, propynylidene is the only $\mathrm{C}_{3} \mathrm{H}_{2}$ isomer with a triplet electronic ground state and the cyclopropenylidene and propadienylidene are in singlet state ${ }^{13-16}$. Moreover, all of them can be interconverted by photolysis ${ }^{17-19}$. The structural characters, thermochemistry, and isomerization of $\mathrm{C}_{3} \mathrm{H}_{2}$ carbenes have been investigated extensively ${ }^{13,18,20-22}$ It was found that the singlet cyclopropenylidene is the most stable isomer among the three species ${ }^{23-26}$, which is lower in energy by about $42-59$ and $59-$ $92 \mathrm{~kJ} / \mathrm{mol}$ than that of propadienylidene and propynylidene, respectively ${ }^{27-31}$. These highly reactive carbene molecules are fundamentally important not only within the context of organic chemistry ${ }^{32,33}$, but also within the context of the chemistry of the interstellar medium ${ }^{34-38}$. Recently, the formation mechanism of the $\mathrm{C}_{3} \mathrm{H}_{2}$ carbenes have been proposed by Goulay et al. using tunable vacuum ultraviolet photoionization and time-resolved mass spectrometry ${ }^{39}$.

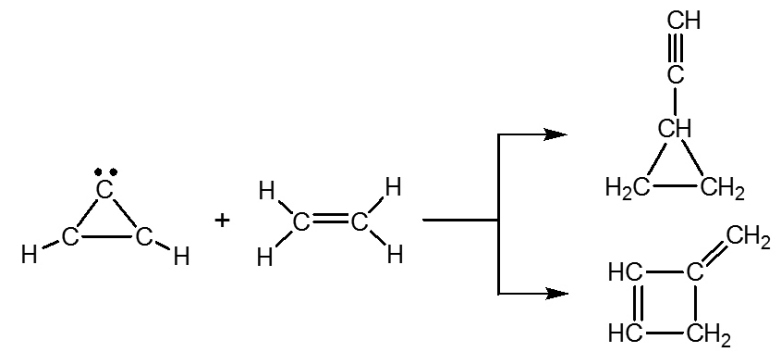

In consideration of the high reactivity and the importance of addition reaction involving $\mathrm{C}_{3} \mathrm{H}_{2}$ carbenes, we have explored the reaction between propadienylidene and alkene using theoretical calculations ${ }^{40}$. However, less is known about the reaction mechanism between cyclopropenylidene and unsaturated hydrocarbon compound to the best of our konwledge. In the absence of experimental information, a theoretical investigation on the above reaction appears to be highly desirable. Therefore, in the present study, the reaction mechanism between cyclopropenylidene and ethylene has been systematically investigated employing the second-order Moller-Plesset perturbation theory (MP2) method so as to better understand the cyclopropenylidene reactivity with unsaturated $\mathrm{C}=\mathrm{C}$ compounds. As a result, for the addition reaction between cyclopropenylidene and ethylene, two different products characterized by three- and four-membered rings have been obtained via two different reaction pathways. The corresponding reaction mechanisms have been clarified detailedly. Hopefully, the present results not only can promote the progress of the relevant experiments, but also can provide insights into the reactivity of $\mathrm{C}_{3} \mathrm{H}_{2}$ carbene with unsaturated compounds containing $\mathrm{C}=\mathrm{C}$ double bonds as well as to enrich the available data for the relevant carbene chemistry.

\section{CALCULATION METHOD}

The MP2 method in combination with $6-311+\mathrm{G}^{*}$ basis set has been employed to locate all the stationary points along the reaction pathways. Frequency analyses have been carried out to confirm the nature of the minima and transition states. Moreover, intrinsic reaction coordinate (IRC) calculations have also been performed to further validate the calculated transition states connecting reactants and products. Additionally, the relevant energy quantities, such as reaction energies and barrier heights, have been corrected with the zero-point vibrational energy (ZPVE) corrections.

To further refine the calculated energy parameters, single point energy calculations have been performed at the $\operatorname{CCSD}(\mathrm{T}) / 6-311+\mathrm{G}^{*}$ level of theory based on the stationary points optimized at the MP2/6-311+G* level of theory. As summarized in Table 1, both levels can give consistent results for the calculated reaction profile of the addition reaction. For the sake of simplicity, the energetic results at the $\operatorname{CCSD}(\mathrm{T}) / 6-311+\mathrm{G}^{*} / / \mathrm{MP} 2 / 6-311+\mathrm{G}^{*}$ level of theory have been mainly discussed below if not noted otherwise.

All the calculations have been performed using Gaussian 98 program $^{41}$.

\section{RESULTS AND DISCUSSION}

As displayed in Figure 1, two possible reaction pathways for the addition reaction between cyclopropenylidene and ethylene have been proposed. Correspondingly, the calculated relative energies for the available stationary points have been summarized in Table 1 .

Scheme 1. The three isomers of $\mathrm{C}_{3} \mathrm{H}_{2}$. 
<smiles>C#CC1CC1</smiles>

Figure 1. The proposed two reaction pathways for the addition reaction between cyclopropenylidene and ethylene.

Table 1: The calculated relative energies (in $\mathrm{kJ} / \mathrm{mol}$ ) with respect to the isolated reactants at the MP2/6-311+G* level of theory considering the ZPVE corr.

\begin{tabular}{|c|c|c|c|c|}
\hline $\begin{array}{c}\text { Pathways } \\
\begin{array}{c}\text { Pathway } \\
(\mathbf{1})\end{array}\end{array}$ & TSa & INTa & TSb & INTb \\
\hline & $77.4(80.6)$ & $-138.5(-113.7)$ & $50.5(50.1)$ & $45.0(36.2)$ \\
\hline & TS1 & P1 & & \\
\hline & $107.5(141.6)$ & $-266.9(-238.4)$ & & \\
\hline $\begin{array}{c}\text { Pathway } \\
(\mathbf{2})\end{array}$ & TS2a & INT2a & TS2b & INT2b \\
\hline & $91.4(85.9)$ & $-215.7(-201.4)$ & $\begin{array}{c}-36 . \\
(-11.6)\end{array}$ & $\begin{array}{c}-17.1(- \\
25.9)\end{array}$ \\
\hline & TS2c & P2 & & \\
\hline & $13.5(17.1)$ & $-295.7(-282.5)$ & & \\
\hline
\end{tabular}

${ }^{a}$ The data in parentheses refer to the results at the $\operatorname{CCSD}(\mathrm{T}) / 6-311+\mathrm{G}^{*} / /$ MP2/6-311+G* level of theory considering the ZPVE corrections.

\subsection{Reaction pathway (1): three-membered ring product channel}

The geometric parameters for the reactants (cyclopropenylidene and ethylene), transition states (TSa, TSb, and TS1), intermediates (INTa and $\mathrm{INTb}$ ), and product (P1) involved in the reaction pathway (1) are displayed in Figure 2. Here, a three-membered ring product $\mathrm{P} 1$ has been obtained in this pathway. The corresponding reaction profile is illustrated in Figure 3.

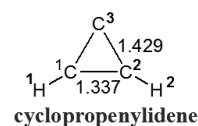

${ }^{3} \mathrm{H}^{4}{ }_{\text {ethylene }}^{4} \frac{4}{1.339} \mathrm{H}^{5}-\mathrm{H}^{5}$

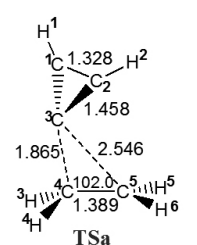

TSa

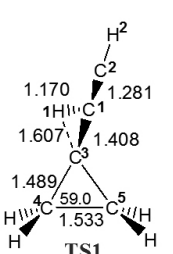

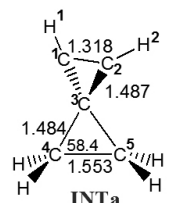

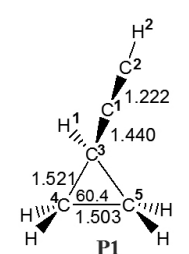

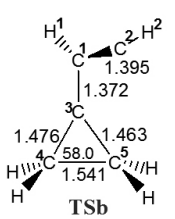

TSb

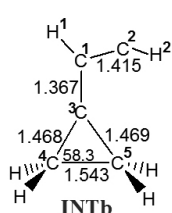

Figure 2. Optimized structures of the reactants (cyclopropenylidene and ethylene), transition states (TSa, TSb, and TS1), intermediates (INTa and $\mathrm{INTb}$ ), and product (P1) in the reaction pathway (1) at the MP2/6-311+G* level of theory, where the bond length and bond angle are in angstrom and degree, respectively.

The formation of the first intermediate INTa occurs along the pathway (1) via a barrier of $80.6 \mathrm{~kJ} / \mathrm{mol}$. As shown in Figure 2, the distances from $\mathrm{C}^{3}$ to $\mathrm{C}^{4}$ and $\mathrm{C}^{5}$ atoms in TSa are 1.865 and $2.546 \AA$, and the bond lengths of $\mathrm{C}^{1}-\mathrm{C}^{2}, \mathrm{C}^{2}$ $\mathrm{C}^{3}$, and $\mathrm{C}^{4}-\mathrm{C}^{5}$ are only slightly changed (1.328 vs $1.337,1.458$ vs $1.429,1.389$ vs $1.339 \AA$ ) compared with the reactants, respectively. The smoothness of the full IRC shown in Figure 4 further indicates that TSa connects reactants and the three-membered ring intermediate INTa.

Due to the existence of tension in three-membered ring, the second step of the pathway (1) is that $\mathrm{C}^{2}-\mathrm{C}^{3}$ bond in INTa opens to form an intermediate INTb via $\mathrm{TSb}$, where the barrier is $50.1 \mathrm{~kJ} / \mathrm{mol}$ relative to the reactants.

In $\mathrm{INTb}$, the $\mathrm{C}^{1}$ atom adopts $s p^{2}$ hybridization and the $\mathrm{C}^{1}-\mathrm{C}^{2}$ and $\mathrm{C}^{1}-\mathrm{C}^{3}$ bonds have been changed to the single and double bonds, respectively. As for the $\mathrm{C}^{2}$ atom, it has a pair of lone electrons, making the INTb exhibit the carbene characters. In other words, INTb is unstable and can rearrange to a more stable structure.
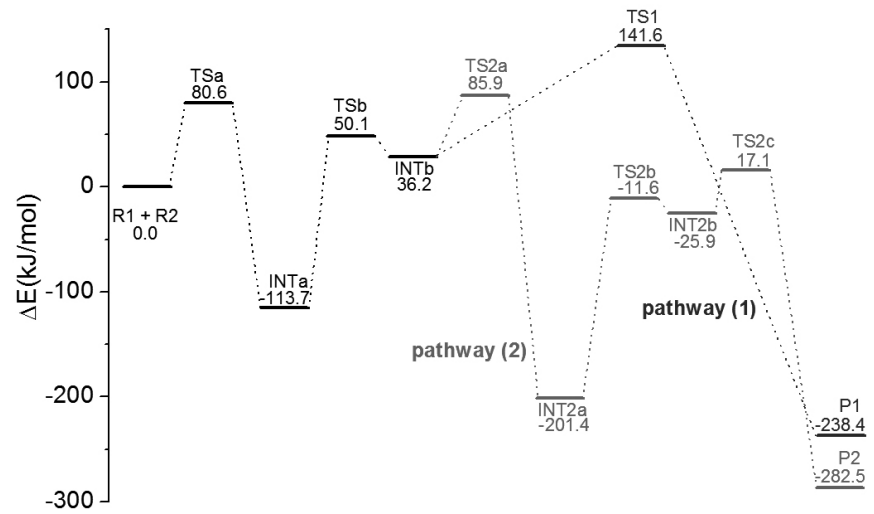

Figure 3. Reaction profiles for the addition reaction pathways (1) and (2) between cyclopropenylidene and ethylene at the $\operatorname{CCSD}(\mathrm{T}) / 6-311+\mathrm{G} * / / \mathrm{MP} 2 / 6$ $311+\mathrm{G}^{*}$ level of theory.

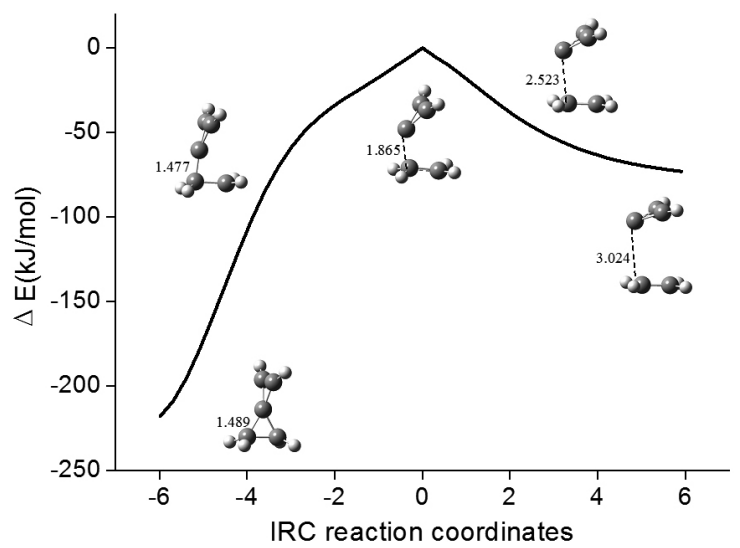

Figure 4. IRC of TSa and geometry evolution.

By shifting the $\mathrm{H}^{1}$ atom on the $\mathrm{C}^{1}$ atom to the adjacent $\mathrm{C}^{3}$ atom, INTb can be converted to P1 via TS1. Here, P1 is the most stable structure along the pathway (1). Obviously, in $\mathrm{P} 1$, the $\mathrm{C}^{3}$ atom is $s p^{3}$ hybridization and both the $\mathrm{C}^{1}$ and $\mathrm{C}^{2}$ atoms are $s p$ hybridization. Therefore, the $\mathrm{C}^{1}-\mathrm{C}^{2}$ bond is a triple bond $(1.222 \AA)$, which is rather shorter than that of the bond between $\mathrm{C}^{1}$ and $\mathrm{C}^{3}$ atoms $(1.440 \AA)$.

As mentioned above, three steps need to surmount transition state in the pathway (1). The corresponding barriers of the three steps are 80.6, 50.1, and $141.6 \mathrm{~kJ} / \mathrm{mol}$ relative to the reactants, respectively. Therefore, the third step is the rate-determining step along the pathway (1).

\subsection{Reaction pathway (2): four-membered ring product channel}

The geometric parameters for the stationary points in the reaction pathway (2) are given in Figure 5. The corresponding reaction profile is illustrated in Figure 3. As illustrated in Figure 5, a four-membered ring product (P2) has been generated in the pathway (2).

Similar to the reaction pathway (1), the common intermediates INTa and 
INTb have been formed successively in the pathway (2). As described above, in the pathway (1), INTb can be converted to P1 via TS1 by shifting the $\mathrm{H}^{1}$ atom on the $C^{1}$ atom to the adjacent $C^{3}$ atom. However, in the pathway (2), INTb can be converted to INT2a via TS2a by shifting the $\mathrm{H}^{1}$ atom on the $\mathrm{C}^{1}$ to the adjacent $\mathrm{C}^{2}$ atom.

As displayed in Figure 5, in INT2a, the $\mathrm{C}^{1}$ atom adopts $s p$ hybridization and the $\mathrm{C}-\mathrm{C}$ bond lengths are $1.319\left(\mathrm{C}^{1}-\mathrm{C}^{2}\right)$ and $1.295 \AA\left(\mathrm{C}^{1}-\mathrm{C}^{3}\right)$, which are intermediate between the general $\mathrm{C}=\mathrm{C}$ double bond (about $1.33 \AA$ ) and $\mathrm{C} \equiv \mathrm{C}$ triple bond (about $1.20 \AA$ ), respectively. Due to the existence of tension in three-membered ring, the fourth step of the pathway (2) is that the $\mathrm{C}^{3}-\mathrm{C}^{5}$ bond in INT2a opens to form an intermediate INT2b via TS2b, where the barrier is $-11.6 \mathrm{~kJ} / \mathrm{mol}$ relative to the reactants. In addition, in TS2b, the distance between $\mathrm{C}^{3}$ and $\mathrm{C}^{5}$ atoms has been elongated to $1.714 \AA$, denoting the rupture of the $\mathrm{C}^{3}-\mathrm{C}^{5}$ bond. On the other hand, the distance between $\mathrm{C}^{1}$ and $\mathrm{C}^{5}$ atoms is $1.953 \AA$, indicating the formation of the $\mathrm{C}^{1}-\mathrm{C}^{5}$ bond.
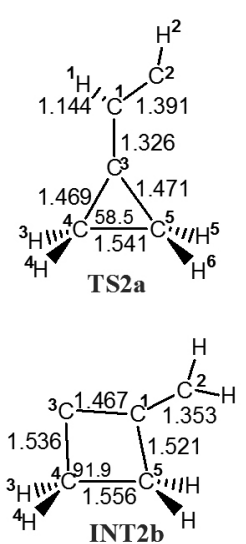

Figure 5. Optimized structures of the transition states (TS2a, TS2b, and TS2c), intermediates (INT2a and INT2b), and product (P2) in the reaction pathway (2) at the MP2/6-311+G* level of theory, where the bond length and bond angle are in angstrom and degree, respectively.

As displayed in Figure 5, INT2b is a four-membered ring structure, and there is a pair of lone electrons on the $\mathrm{C}^{3}$ atom. For this reason, INT2b is characteristic of carbene. The fifth step of the pathway (2) is that one $\mathrm{H}$ atom on the $\mathrm{C}^{4}$ atom of INT2b is transfered to the $\mathrm{C}^{3}$ atom to form a more stable structure $\mathrm{P} 2$ via TS2c, where the barrier is $17.1 \mathrm{~kJ} / \mathrm{mol}$ relative to the reactants. Based on the analysis of the imaginary frequency and the calculation of the IRC, it can be proved that TS2c connects the INT2 $\mathrm{b}$ and $\mathrm{P} 2$ indeed.

In $\mathrm{P} 2$, the bond lengths of $\mathrm{C}^{1}-\mathrm{C}^{2}$ and $\mathrm{C}^{3}-\mathrm{C}^{4}$ are 1.340 and $1.361 \AA$, respectively, which are slightly longer than that of the normal $\mathrm{C}=\mathrm{C}$ double bond. At the same time, the bond length of $\mathrm{C}^{1}-\mathrm{C}^{3}$ is $1.476 \AA$, which is slightly shorter than that of the normal C-C single bond. Moreover, further energy analyses suggest that P2 is lower in energy by about $282.5 \mathrm{~kJ} / \mathrm{mol}$ than those of reactants. From the calculated bond length and the stability, P2 is a stable conjugated diene and it is the ultima product of the pathway (2).

In summary, the barrier heights of the five steps in pathway (2) are 80.6 $50.1,85.9,-11.6$, and $17.1 \mathrm{~kJ} / \mathrm{mol}$ relative to the reactants, respectively. Therefore, the third step is the rate-determining step along the pathway (2).

\section{3 Comparisons of the two reaction pathways}

As mentioned above, three- and four-membered ring products can be produced between cyclopropenylidene and ethylene through two different reaction pathways. The barrier heights of the rate-determining step in reaction pathways (1) and (2) are 141.6 and $85.9 \mathrm{~kJ} / \mathrm{mol}$ relative to the reactants, respectively. Therefore, the reaction pathway (2) should be the most favorable reaction to occur kinetically. On the other hand, the corresponding products P1 and P2 have been stabilized by about 238.4 and $282.5 \mathrm{~kJ} / \mathrm{mol}$ relative to the reactants, respectively. Therefore, the most favorable product $\mathrm{P} 2$ should be confirmed, implying that the reaction pathway (2) is also a favorable channel from the thermodynamic viewpoint.

\section{CONCLUSIONS}

In this study, the reaction mechanism between cyclopropenylidene and ethylene has been systematically investigated employing the MP2/6-311+G* level of theory. It was found that two products $\mathrm{P} 1$ and $\mathrm{P} 2$ characterized by the three- and four-membered ring structures have been produced via two different reaction pathways. The reaction pathway (2) should be the most favorable reaction to occur kinetically. Moreover, the corresponding products $\mathrm{P} 1$ and P2 have been stabilized by 238.4 and $282.5 \mathrm{~kJ} / \mathrm{mol}$ relative to the reactants, respectively. Therefore, the pathway (2) should be the most favorable reaction to occur from the thermodynamic viewpoints.

\section{ACKNOWLEDGMENT}

This work is supported by NSFC (21003082), the Project of Shandong Province Higher Educational Science and Technology Program (J09LB01, J09LB17), and the Foundation for Outstanding Young Scientist in Shandong Province (BS2009HZ014, BS2010NJ009).

\section{REFERENCES}

1. M. Mitani, Y. Kobanashi, K. Koyama, J. Chem. Soc., Perkin Trans I 653, (1995).

2. M. Garcia, C. D. Campo, E. F. Llama, Tetrahedron Lett. 49, 8433, (1993).

3. M. Garcia, C. D. Campo, E. F. Llama, J. Chem. Soc., Perkin Trans I 1771, (1995).

4. R. R. Kostikov, A. F. Khlebnikov, V. Y. Bespalov, J. Phys. Org. Chem. 6, 83, (1993).

5. Y. Wang, H. Li, Acta Phys-Chim. Sin. 20, 1339, (2004).

6. P. J. Stang, J. Am. Chem. Res. 15, 348, (1982).

7. X. H. Lu, Y. X. Wang, J. Phys. Chem. A 107, 7885, (2003).

8. X. H. Lu, Y. X. Wang, J. Mole. Struct. (THEOCHEM) 686, 207, (2004).

9. Y. Apeloig, M. Karni, P. J. Stang, J. Am. Chem. Soc. 105, 4781, (1983).

10. D. P. Fox, P. J. Stang, Y. Apeloig, M. Karni, J. Am. Chem. Soc. 108, 750, (1986).

11. X. J. Tan, P. Li, W. H. Wang, G. X. Zheng, X. L. Yang, Struct. Chem. 20, $671,(2009)$.

12. X. J. Tan, P. Li, W. H. Wang, G. X. Zheng, Q. F. Wang, J. Serb. Chem. Soc. $75,649,(2010)$

13. R. Herges, A. Mebel, J. Am. Chem. Soc. 116, 8229, (1994).

14. G. Maier, H. P. Reisenauer, W. Schwab, P. Carsky, B. A. Hess, L. J. Schaad, J. Am. Chem. Soc. 109, 5183, (1987).

15. R. A. Seburg, J. T. DePinto, E. V. Patterson, R. J. McMahon, J. Am. Chem. Soc. 117, 835, (1995).

16. T. MacAllister, A. Nicholson, J. Chem. Soc., Faraday Trans. 77, 821, (1981).

17. R. A. Seburg, R. MacMahon, Angew. Chem., Int. Ed. Engl. 34, 2009, (1995).

18. R. A. Seburg, E. V. Patterson, J. F. Stanton, R. J. McMahon, J. Am. Chem. Soc. 119, 5847, (1997).

19. G. Maier, H. P. Reisenauer, W. Schwab, P. Carsky, V. Spirko, B. A. Hess, L. J. Schaad, J. Chem. Phys. 91, 4763, (1989).

20. V. Juana, E. H. Michael, G. Jurgen, F. S. John, J. Phys. Chem. A 113 , 12447, (2009).

21. C. A. Taatjes, S. J. Klippenstein, N. Hansen, J. A. Miller, T. A. Cool, J. Wang, M. E. Law, P. R. Westmoreland, Phys. Chem. Chem. Phys. 7, 806, (2005).

22. K. C. Lau, C. Y. Ng, Chin. J. Chem. Phys. 19, 29, (2006).

23. R. Gleiter, R. Hoffmann, J. Am. Chem. Soc. 90, 5457, (1968).

24. R. Shepard, A. Banerjee, J. Simons, J. Am. Chem. Soc. 101, 6174, (1979).

25. T. J. Lee, A. Bunge, H. F. Schaefer, J. Am. Chem. Soc. 107, 137, (1985).

26. J. A. Montgomery, J. W. Ochterski, G. A. Petersson, J. Chem. Phys. 101, $5900,(1994)$

27. W. J. Hehre, J. A. Pople, W. A. Lathan, L. Radom, E. Wasserman, Z. R. Wasserman, J. Am. Chem. Soc. 98, 4378, (1976).

28. V. Jonas, M. Bohme, G. Frenking, J. Phys. Chem. 96, 1640, (1992)

29. J. Takahashi, K. Yamashita, J. Chem. Phys. 104, 6613, (1996).

30. Q. Fan, G. V. Pfeiffer, Chem. Phys. Lett. 162, 472, (1989).

31. S. P. Walch, J. Chem. Phys. 103, 7064, (1995).

32. W. Kirmse, Carbene Chemistry 2nd ed, Academic Press: New York, 1971.

33. M. Jones, R. A. Moss, Carbenes Wiley: New York, 1973.

34. E. Herbst, Angew. Chem. Int. Ed. Engl. 29, 595, (1990). 
35. E. Herbst, L. M. Leung, Astrophys. J. Suppl. Ser. 69, 271, (1989).

36. G. Winnewisser, Top Curr. Chem. 99, 39, (1981).

37. R. Hayatsu, E. Anders, Top Curr. Chem. 99, 1, (1981).

38. P. Thaddeus, C. A. Gottlieb, R. Mollaaghababa, J. M. Vrtilek, J. Chem. Soc. Faraday Trans. 89, 2125, (1993).
39. F. Goulay, J. T. Adam, G. Meloni, M. S. Talitha, L. O. David, A. T. Craig, V. Luc, R. L. Stephen, J. Am. Chem. Soc. 131, 993, (2009).

40. X. J. Tan, P. Li, W. H. Wang, S. K. Liu, F. Wang, H. L. Wang, Struct. Chem. 22, 1031, (2011)

41. M. J. Frisch, et al., Gaussian 98, Gaussian Inc., Pittsburgh, PA, 1998. 